\title{
OPINIÃO DOS PAIS SOBRE A VOZ, CARACTERÍSTICAS DE COMPORTAMENTO E DE PERSONALIDADE DE SEUS FILHOS
}

\author{
Parents opinion on the voice and on behavior \\ and personality characteristics of their children
}

\author{
Angela von Fritsch ${ }^{(1)}$, Gisele Oliveira ${ }^{(2)}$, Mara Behlau ${ }^{(3)}$
}

\begin{abstract}
RESUMO
Objetivo: verificar como os pais percebem e descrevem seus filhos com relação à voz e às características de comportamento e personalidade. Métodos: participaram do estudo 66 pais de crianças entre 6 e 9 anos, de ambos os sexos, os quais responderam a um questionário com 28 questões que investigavam características de voz, comportamento e personalidade de seus filhos. Resultados: os resultados indicaram que a maioria dos pais $(90,9 \%)$ se mostra satisfeita com o som da voz de seu filho(a). Somente $9,1 \%$ dos pais caracterizaram a voz de seu filho como sendo pior que a das demais crianças e $31,8 \%$ achou que seu filho(a) fala muito mais se comparado aos colegas. Aproximadamente um quarto $(22,7 \%)$ dos pais observou que o volume de voz utilizado por seus filhos é aumentado. Os pais que caracterizaram seus filhos como sendo mais falantes também perceberam a voz deles como sendo mais aguda $(p=0,013)$. O volume de voz aumentado mostrou correlação positiva com agitação $(p=0,044)$, inquietação $(p=0,005)$, sociabilidade $(p=0,021)$, menos quantidade de horas dormidas $(p=0,013)$ e extroversão $(p=0,014)$. Crianças caracterizadas como sendo mais calmas $(p=0,011)$ e menos argumentativas $(p=0,044)$ são também menos falantes na comparação com outras crianças. Conclusão: em geral, os pais parecem perceber características vocais em seus filhos, têm forte tendência a considerar seus filhos sensíveis, observadores e exigentes quanto a si mesmos, além de perceberem relação entre volume de voz e características de comportamento e personalidade.
\end{abstract}

DESCRITORES: Disfonia; Voz; Pais; Crianças

(1) Fonoaudióloga; Consultório particular, São Paulo, Brasil, Especializanda em Voz pelo Centro de Estudos da Voz.

(2) Fonoaudióloga; Professora do Curso de Especialização em Voz do Centro de Estudos da Voz, CEV, São Paulo, SP, Brasil; Especialista em Voz pelo Conselho Federal de Fonoaudiologia, com curso no Centro de Estudos da Voz; Doutoranda em Distúrbios da Comunicação Humana na Universidade Federal de São Paulo - Escola Paulista de Medicina.

(3) Fonoaudióloga; Docente permanente do Curso de PósGraduação em Distúrbios da Comunicação Humana na Universidade Federal de São Paulo - Escola Paulista de Medicina, UNIFESP/EPM, São Paulo, SP, Brasil; Professora do Curso de Especialização em Voz do Centro de Estudos da Voz, CEV, São Paulo, SP, Brasil; Especialista em Voz pelo Conselho Federal de Fonoaudiologia; Doutora em Distúrbios da Comunicação Humana pela Universidade Federal de São Paulo - Escola Paulista de Medicina.

Conflito de interesses: inexistente

\section{INTRODUÇÃO}

A voz humana, embora seja uma função neurofisiológica inata que se aprimora juntamente com o desenvolvimento orgânico do indivíduo, depende de uma complexa atividade de todos os músculos que servem à sua produção, da integridade dos tecidos do aparelho fonador e constitui-se em uma das extensões mais fortes da personalidade ${ }^{1}$

Se no adulto os desvios nesse complexo sistema vocal são frequentemente definidos pela própria queixa do falante, na criança eles passam muitas vezes despercebidos aos seus pais e a elas próprias por serem costumeiramente confundidos com sintomas de infecções de vias aéreas superiores ou com qualidade normal da voz. Parece também que pais e educadores são mais atentos a identificar nas crianças problemas de fala e linguagem em detrimento das alterações de $\mathrm{voz}^{2,3}$. 
O tênue equilíbrio do que é esperado na voz infantil - que tenha qualidade vocal, frequência, intensidade e flexibilidade adequadas para a idade e que seja agradável ao ouvinte - é posto à prova diariamente na escola, com os amigos, irmãos, nos esportes, já que o uso da voz muitas vezes passa a ser excessivo em relação às possibilidades da laringe infantil ${ }^{4}$. $\mathrm{O}$ aumento da intensidade parece ser um recurso muito utilizado pelas crianças que, se usado de forma prolongada, pode levar a alterações dos demais parâmetros (qualidade vocal rouca, frequência grave, diminuição da flexibilidade).

Disfonias na infância são quadros frequentes. Pesquisas apontam uma incidência de 6 a 37\%, sendo que a lesão mais frequente são os nódulos vocais. O pico de maior incidência ocorre entre cinco e dez anos ${ }^{5}$. Os desvios vocais em crianças são geralmente associados a um comportamento vocal abusivo e excessivo, como falar demais, falar muito forte e falar muito agudo 6 . Os pais, que convivem com seus filhos, dificilmente levam ao pediatra, ao professor ou ao fonoaudiólogo a queixa de que seu filho fala alto ou pior, de que é rouco.

A literatura apresenta crianças com nódulos vocais como sendo falantes e que gostam de brincadeiras que envolvam o uso da voz ${ }^{7}$; "extrovertidas e impulsivas" ou "contraídas, ansiosas e reprimidas" e que têm muitos amigos, que passam tempo com os amigos com mais frequência e que se envolvem mais em atividades organizacionais, que demandam maior uso da voz ${ }^{5}$. Algumas pesquisas ${ }^{8}$ descrevem o grupo com nódulos vocais estudado como sendo ansioso, reativo ao stress e agressivo.

Alguns autores ${ }^{9}$ investigaram, por meio de entrevistas dirigidas, o impacto de uma alteração de voz na qualidade de vida de crianças, e descrevem em seu estudo que a disfonia crônica afeta os domínios físico, social/funcional e emocional ${ }^{10}$. Os autores acreditam que o impacto de uma disfonia na vida de uma criança pode ser subestimado e assim atrasar a busca de intervenção. É possível supor que o atraso na busca de intervenção ocorra também por faltarem aos pais informações que permitam identificar os sinais de risco e os transtornos vocais em seus filhos².

O objetivo do presente estudo é verificar como os pais percebem e descrevem seus filhos com relação à voz e às características de comportamento e personalidade.

\section{MÉTODOS}

O tipo de estudo realizado foi o ensaio clínico aleatório.

Participaram do presente estudo 66 pais, sendo $31(47 \%)$ de crianças do sexo feminino e 35 (53\%) de crianças do sexo masculino que responderam a um questionário com 28 perguntas que investigavam aspectos de voz, comportamento e personalidade de seu filho, considerando os últimos seis meses e comparando-o com crianças da mesma faixa etária. A faixa etária das crianças variou de 6 a 9 anos, com média de 7,5 anos. Todas as crianças frequentavam regularmente uma escola de ensino fundamental particular, na cidade de São Paulo, do 1ㅇ ao $3^{\circ}$ ano. Quanto ao responsável por responder ao questionário, 56 (85\%) foram respondidos pela mãe e $11(16,6 \%)$ pelo pai.

O questionário continha 28 perguntas, 4 sobre aspectos vocais (som da voz, volume, tom e quantidade de uso de voz), 24 sobre aspectos comportamentais e de personalidade (agitação, inquietação, necessidade de solidão, tensão/ansiedade, exigência consigo mesmo, medo, preocupação, acessos de raiva, ciúmes, desrespeito a regras, escapar da tarefa argumentando, ter sempre a última palavra, obedecer diante de ameaça de castigo, sensação de injustiça, impulsividade, mau-humor ou irritabilidade, gritar quando se aborrece, ficar bravo quando sua vontade não é satisfeita, quantidade de horas dormidas, introversão, timidez, sensibilidade, ser observador e extroversão) (Figura 1).

Este trabalho foi aprovado pelo Comitê de Ética do Centro de Estudos da Voz - CEV (parecer $515 / 07$ ), e os pais envolvidos na pesquisa assinaram o Termo de Consentimento Livre e Esclarecido.

As questões foram respondidas por meio de uma escala do tipo Likert de 5 pontos, a saber: "muito menos que outras crianças", "menos que outras crianças, "semelhante a outras crianças", "mais que outras crianças" e "muito mais que outras crianças". Para a análise estatística, todas as questões "menos" foram tratadas como -1 , as questões "semelhante" como 0, e as questões "mais", como +1 . Para os aspectos vocais foram apresentadas todas as opiniões dos pais; já quanto ao comportamento e personalidade foram selecionadas apenas as respostas que indicavam ocorrência maior ("mais que outras crianças") para facilitar a discussão dos achados. Para a distinção de gênero, foram apresentadas todas as ocorrências maiores ("mais que outras crianças").

Foram analisadas as ocorrências sobre os aspectos observados e realizadas correlações entre os aspectos vocais e os de comportamento e personalidade e entre todos os aspectos do questionário e o gênero das crianças (masculino e feminino).

Para a análise dos dados foram utilizados os softwares SPSS V11. 5, Minitab 14 e Excel XP. O nível de significância adotado foi de 0,05 (5\%).e o resultado que apresentou significância estatística aparece com o valor $p$ em vermelho para melhor visualização. 


\section{Questionário da opinião dos pais sobre a voz, características de personalidade e de comportamento de seus filhos}

você deve responder a esse questionário pensando no comportamento de seu filho nos últimos seis meses e comparando-o com crianças da mesma faixa etária

\begin{tabular}{|c|c|c|c|c|}
\hline \multicolumn{3}{|l|}{ sexo $M$} & idade & \\
\hline & \multicolumn{2}{|c|}{ responsável pelo questionário: } \\
\hline série & & & pai & mãe \\
\hline \multicolumn{5}{|c|}{ 1- você considera o som da voz do seu filho(a) } \\
\hline $\begin{array}{l}\text { muito pior que das } \\
\text { outras crianças }\end{array}$ & $\begin{array}{l}\text { um pouco pior que } \\
\text { das outras crianças }\end{array}$ & $\begin{array}{l}\text { semelhante ao das } \\
\text { outras crianças }\end{array}$ & $\begin{array}{l}\text { um pouco melhor que } \\
\text { das outras crianças }\end{array}$ & $\begin{array}{l}\text { muito melhor que das } \\
\text { outras crianças }\end{array}$ \\
\hline \multicolumn{5}{|c|}{ 2-você acha que o volume da voz de seu filho é } \\
\hline $\begin{array}{l}\text { muito mais baixo } \\
\text { que das outras } \\
\text { crianças }\end{array}$ & $\begin{array}{l}\text { um pouco mais } \\
\text { baixo que das outras } \\
\text { crianças }\end{array}$ & $\begin{array}{l}\text { semelhante ao das } \\
\text { outras crianças }\end{array}$ & $\begin{array}{l}\text { um pouco mais alto } \\
\text { que das outras } \\
\text { crianças }\end{array}$ & $\begin{array}{l}\text { muito mais alto que } \\
\text { das outras crianças }\end{array}$ \\
\hline \multicolumn{5}{|c|}{ 3-você acha que o tom da voz de seu filho é } \\
\hline $\begin{array}{l}\text { muito mais grosso } \\
\text { que das outas } \\
\text { crianças }\end{array}$ & $\begin{array}{l}\text { um pouco mais } \\
\text { grosso que das } \\
\text { outras crianças }\end{array}$ & $\begin{array}{l}\text { semelhante ao das } \\
\text { outras crianças }\end{array}$ & $\begin{array}{l}\text { um pouco mais fino } \\
\text { que das outras } \\
\text { crianças }\end{array}$ & $\begin{array}{l}\text { muito mais fino que } \\
\text { das outras crianças }\end{array}$ \\
\hline
\end{tabular}

4-você acha que a quantidade de fala de seu filho durante um dia é

\begin{tabular}{|l|l|l|l|l}
\hline $\begin{array}{l}\text { muito menor que a } \\
\text { das outras crianças }\end{array}$ & $\begin{array}{l}\text { um pouco menor } \\
\text { que a das outras } \\
\text { crianças }\end{array}$ & $\begin{array}{l}\text { semelhante à das } \\
\text { outras crianças }\end{array}$ & $\begin{array}{l}\text { um pouco maior que } \\
\text { a das outras crianças }\end{array}$ & $\begin{array}{l}\text { muito maior que autras crianças } \\
\text { as an }\end{array}$ \\
\hline
\end{tabular}

5- você acha que o seu/sua filho(a) é agitado(a)?

\begin{tabular}{|l|l|l|l|l}
\hline $\begin{array}{l}\text { muito menos que as } \\
\text { outras crianças }\end{array}$ & $\begin{array}{l}\text { um pouco menos } \\
\text { que as outras } \\
\text { criancas }\end{array}$ & $\begin{array}{l}\text { semelhante às outras } \\
\text { crianças }\end{array}$ & $\begin{array}{l}\text { um pouco mais que } \\
\text { as outras crianças }\end{array}$ & $\begin{array}{l}\text { muito mais que as } \\
\text { outras crianças }\end{array}$
\end{tabular}

6- você acha que seu/sua filho(a) tem dificuldade de parar quando solicitado(a)

\begin{tabular}{|l|l|l|l|l}
\hline $\begin{array}{l}\text { muito menos que as } \\
\text { outras crianças }\end{array}$ & $\begin{array}{l}\text { um pouco menos } \\
\text { que as outras }\end{array}$ & $\begin{array}{l}\text { semelhante às outras } \\
\text { crianças }\end{array}$ & $\begin{array}{l}\text { um pouco mais que } \\
\text { as outras crianças }\end{array}$ & $\begin{array}{l}\text { muito mais que as } \\
\text { outras crianças }\end{array}$
\end{tabular}

7- você acha que seu/sua filho(a) gosta de estar com os amigos

\begin{tabular}{|l|l|l|l|l}
\hline $\begin{array}{l}\text { muito menos que as } \\
\text { outras crianças }\end{array}$ & $\begin{array}{l}\text { um pouco menos } \\
\text { que as outras } \\
\text { crianças }\end{array}$ & $\begin{array}{l}\text { semelhante às outras } \\
\text { crianças }\end{array}$ & $\begin{array}{l}\text { um pouco mais que } \\
\text { as outras crianças }\end{array}$ & $\begin{array}{l}\text { muito mais que as } \\
\text { outras crianças }\end{array}$ \\
\hline
\end{tabular}

8- você acha que a opinião dos outros inibe o seu/sua filho(a)

\begin{tabular}{|l|l|l|l|l}
\hline $\begin{array}{l}\text { muito menos que as } \\
\text { outras crianças }\end{array}$ & $\begin{array}{l}\text { um pouco menos } \\
\text { que as outras } \\
\text { criancas }\end{array}$ & $\begin{array}{l}\text { semelhante às outras } \\
\text { crianças }\end{array}$ & $\begin{array}{l}\text { um pouco mais que } \\
\text { as outras crianças }\end{array}$ & $\begin{array}{l}\text { muito mais que as } \\
\text { outras crianças }\end{array}$ \\
\hline
\end{tabular}

9- você acha que seu/sua filho(a) é tímido(a)

\begin{tabular}{|l|l|l|l|l}
\hline $\begin{array}{l}\text { muito menos que as } \\
\text { outras crianças }\end{array}$ & $\begin{array}{l}\text { um pouco menos } \\
\text { que as outras } \\
\text { crianças }\end{array}$ & $\begin{array}{l}\text { semelhante às outras } \\
\text { crianças }\end{array}$ & $\begin{array}{l}\text { um pouco mais que } \\
\text { as outras crianças }\end{array}$ & $\begin{array}{l}\text { muito mais que as } \\
\text { outras crianças }\end{array}$ \\
\hline
\end{tabular}

10- você acha que seu/sua filho(a) é sensível

\begin{tabular}{|l|l|l|l|l}
\hline $\begin{array}{l}\text { muito menos que as } \\
\text { outras crianças }\end{array}$ & $\begin{array}{l}\text { um pouco menos } \\
\text { que as outras } \\
\text { crianças }\end{array}$ & $\begin{array}{l}\text { semelhante às outras } \\
\text { crianças }\end{array}$ & $\begin{array}{l}\text { um pouco mais que } \\
\text { as outras crianças }\end{array}$ & $\begin{array}{l}\text { muito mais que as } \\
\text { outras crianças }\end{array}$
\end{tabular}

11- você acha que seu/sua filho(a) é observador(a)

\begin{tabular}{|l|l|l|l|l|}
\hline $\begin{array}{l}\text { muito menos que as } \\
\text { outras crianças }\end{array}$ & $\begin{array}{l}\text { um pouco menos } \\
\text { que as outras } \\
\text { crianças }\end{array}$ & $\begin{array}{l}\text { semelhante às outras } \\
\text { crianças }\end{array}$ & $\begin{array}{l}\text { um pouco mais que } \\
\text { as outras crianças }\end{array}$ & $\begin{array}{l}\text { muito mais que as } \\
\text { outras crianças }\end{array}$ \\
\hline
\end{tabular}

12- você acha que seu/sua filho(a) precisa de momentos de solidão

\begin{tabular}{|l|l|l|l|l}
\hline $\begin{array}{l}\text { muito menos que as pouco menos } \\
\text { outras crianças }\end{array}$ & $\begin{array}{l}\text { semelhante às outras } \\
\text { crianças }\end{array}$ & $\begin{array}{l}\text { um pouco mais que outras } \\
\text { as outras crianças }\end{array}$ & $\begin{array}{l}\text { muito mais que as } \\
\text { outras crianças }\end{array}$
\end{tabular}


15- você acha que seu/sua filho(a) é medroso(a)

\begin{tabular}{|l|l|l|l|l}
\hline $\begin{array}{l}\text { muito menos que as } \\
\text { outras crianças }\end{array}$ & $\begin{array}{l}\text { um pouco menos } \\
\text { que as outras } \\
\text { criancas }\end{array}$ & $\begin{array}{l}\text { semelhante às outras } \\
\text { crianças }\end{array}$ & $\begin{array}{l}\text { um pouco mais que } \\
\text { as outras crianças }\end{array}$ & $\begin{array}{l}\text { muito mais que as } \\
\text { outras crianças }\end{array}$ \\
\hline
\end{tabular}

16- você acha que seu/sua filho(a) é preocupado(a)

\begin{tabular}{|l|l|l|l|l}
\hline $\begin{array}{l}\text { muito menos que as } \\
\text { outras crianças }\end{array}$ & $\begin{array}{l}\text { um pouco menos } \\
\text { que as outras } \\
\text { crianças }\end{array}$ & $\begin{array}{l}\text { semelhante às outras } \\
\text { crianças }\end{array}$ & $\begin{array}{l}\text { um pouco mais que } \\
\text { as outras crianças }\end{array}$ & $\begin{array}{l}\text { muito mais que as } \\
\text { outras crianças }\end{array}$ \\
\hline
\end{tabular}

17- você acha que seu/sua filho(a) tem acessos de raiva

\begin{tabular}{|l|l|l|l|l|}
\hline $\begin{array}{l}\text { muito menos que as } \\
\text { outras crianças }\end{array}$ & $\begin{array}{l}\text { um pouco menos } \\
\text { que as outras } \\
\text { crianças }\end{array}$ & $\begin{array}{l}\text { semelhante às outras } \\
\text { crianças }\end{array}$ & $\begin{array}{l}\text { um pouco mais que } \\
\text { as outras crianças }\end{array}$ & $\begin{array}{l}\text { muito mais que as } \\
\text { outras crianças }\end{array}$ \\
\hline
\end{tabular}

18- você acha que seu/sua filho(a) fica com ciúmes

\begin{tabular}{|l|l|l|l|l}
\hline $\begin{array}{l}\text { muito menos que as } \\
\text { outras crianças }\end{array}$ & $\begin{array}{l}\text { um pouco menos } \\
\text { que as outras } \\
\text { crianças }\end{array}$ & $\begin{array}{l}\text { semelhante às outras } \\
\text { crianças }\end{array}$ & $\begin{array}{l}\text { um pouco mais que } \\
\text { as outras crianças }\end{array}$ & $\begin{array}{l}\text { muito mais que as } \\
\text { outras crianças }\end{array}$ \\
\hline
\end{tabular}

19- você acha que seu/sua filho(a) desrespeita regras

\begin{tabular}{|l|l|l|l|l|}
\hline $\begin{array}{l}\text { muito menos que as } \\
\text { outras crianças }\end{array}$ & $\begin{array}{l}\text { um pouco menos } \\
\text { que as outras } \\
\text { crianças }\end{array}$ & $\begin{array}{l}\text { semelhante às outras } \\
\text { crianças }\end{array}$ & $\begin{array}{l}\text { um pouco mais que } \\
\text { as outras crianças }\end{array}$ & $\begin{array}{l}\text { muito mais que as } \\
\text { outras crianças }\end{array}$ \\
\hline
\end{tabular}

20- você acha que seu/sua filho(a) tenta escapar da tarefa argumentando

\begin{tabular}{|l|l|l|l|l|}
\hline $\begin{array}{l}\text { muito menos que as } \\
\text { outras crianças }\end{array}$ & $\begin{array}{l}\text { um pouco menos } \\
\text { que as outras } \\
\text { crianças }\end{array}$ & $\begin{array}{l}\text { semelhante às outras } \\
\text { crianças }\end{array}$ & $\begin{array}{l}\text { um pouco mais que } \\
\text { as outras crianças }\end{array}$ & $\begin{array}{l}\text { muito mais que as } \\
\text { outras crianças }\end{array}$ \\
\hline
\end{tabular}

21- você acha que seu/sua filh(a) tem sempre a última palavra

\begin{tabular}{|l|l|l|l|l}
\hline $\begin{array}{l}\text { muito menos que as } \\
\text { outras crianças }\end{array}$ & $\begin{array}{l}\text { um pouco menos } \\
\text { que as outras } \\
\text { crianças }\end{array}$ & $\begin{array}{l}\text { semelhante às outras } \\
\text { crianças }\end{array}$ & $\begin{array}{l}\text { um pouco mais que } \\
\text { as outras crianças }\end{array}$ & $\begin{array}{l}\text { muito mais que as } \\
\text { outras crianças }\end{array}$ \\
\hline
\end{tabular}

22- você acha que seu/sua filho(a) só obedece diante de ameaça de castigo

\begin{tabular}{|l|l|l|l|l|}
\hline $\begin{array}{l}\text { muito menos que as } \\
\text { outras crianças }\end{array}$ & $\begin{array}{l}\text { um pouco menos } \\
\text { que as outras } \\
\text { criancas }\end{array}$ & $\begin{array}{l}\text { semelhante às outras } \\
\text { crianças }\end{array}$ & $\begin{array}{l}\text { um pouco mais que } \\
\text { as outras crianças }\end{array}$ & $\begin{array}{l}\text { muito mais que as } \\
\text { outras crianças }\end{array}$ \\
\hline
\end{tabular}

\begin{tabular}{|c|c|c|c|c|}
\hline \multirow{2}{*}{\multicolumn{5}{|c|}{ 23- você acha que seu/sua filho(a) se sente injustiçado }} \\
\hline & & & & \\
\hline $\begin{array}{l}\text { muito menos que as } \\
\text { outras crianças }\end{array}$ & $\begin{array}{l}\text { um pouco menos } \\
\text { que as outras } \\
\text { crianças }\end{array}$ & $\begin{array}{l}\text { semelhante às outras } \\
\text { crianças }\end{array}$ & $\begin{array}{l}\text { um pouco mais que } \\
\text { as outras crianças }\end{array}$ & $\begin{array}{l}\text { muito mais que as } \\
\text { outras crianças }\end{array}$ \\
\hline \multicolumn{5}{|c|}{ 24- você acha que seu/sua filho(a) é impulsivo ou age sem pensar } \\
\hline $\begin{array}{l}\text { muito menos que as } \\
\text { outras crianças }\end{array}$ & $\begin{array}{l}\text { um pouco menos } \\
\text { que as outras } \\
\text { crianças }\end{array}$ & $\begin{array}{l}\text { semelhante às outras } \\
\text { crianças }\end{array}$ & $\begin{array}{l}\text { um pouco mais que } \\
\text { as outras crianças }\end{array}$ & $\begin{array}{l}\text { muito mais que as } \\
\text { outras crianças }\end{array}$ \\
\hline \multicolumn{5}{|c|}{ 25- você acha que seu/sua filho(a) tem mau-humor ou irrita-se } \\
\hline $\begin{array}{l}\text { muito menos que as } \\
\text { outras crianças }\end{array}$ & $\begin{array}{l}\text { um pouco menos } \\
\text { que as outras } \\
\text { crianças }\end{array}$ & $\begin{array}{l}\text { semelhante às outras } \\
\text { crianças }\end{array}$ & $\begin{array}{l}\text { um pouco mais que } \\
\text { as outras crianças }\end{array}$ & $\begin{array}{l}\text { muito mais que as } \\
\text { outras crianças }\end{array}$ \\
\hline \multicolumn{5}{|c|}{ 26- você acha que seu/sua filho(a) tem o hábito de gritar quando se aborrece } \\
\hline $\begin{array}{l}\text { muito menos que as } \\
\text { outras crianças }\end{array}$ & $\begin{array}{l}\text { um pouco menos } \\
\text { que as outras } \\
\text { crianças }\end{array}$ & $\begin{array}{l}\text { semelhante às outras } \\
\text { crianças }\end{array}$ & $\begin{array}{l}\text { um pouco mais que } \\
\text { as outras crianças }\end{array}$ & $\begin{array}{l}\text { muito mais que as } \\
\text { outras crianças }\end{array}$ \\
\hline \multicolumn{5}{|c|}{ 27- você acha que seu/sua filho(a) fica bravo quando não tem a sua vontade satisfeita } \\
\hline $\begin{array}{l}\text { muito menos que as } \\
\text { outras crianças }\end{array}$ & $\begin{array}{l}\text { um pouco menos } \\
\text { que as outras } \\
\text { crianças }\end{array}$ & $\begin{array}{l}\text { semelhante às outras } \\
\text { crianças }\end{array}$ & $\begin{array}{l}\text { um pouco mais que } \\
\text { as outras crianças }\end{array}$ & $\begin{array}{l}\text { muito mais que das } \\
\text { outras crianças }\end{array}$ \\
\hline \multicolumn{5}{|c|}{ 28- você acha que a quantidade de horas dormidas de seu /sua filho(a) é } \\
\hline $\begin{array}{l}\text { muito menos que a } \\
\text { das outras crianças }\end{array}$ & $\begin{array}{l}\text { um pouco menos } \\
\text { que a das outras } \\
\text { crianças }\end{array}$ & $\begin{array}{l}\text { semelhante à das } \\
\text { outras crianças }\end{array}$ & $\begin{array}{l}\text { um pouco mais que } \\
\text { a das outras crianças }\end{array}$ & $\begin{array}{l}\text { muito mais que a as } \\
\text { outras crianças }\end{array}$ \\
\hline
\end{tabular}

Figura 1 - Questionário da opinião dos pais sobre a voz, características de personalidade e de comportamento de seus filhos 


\section{RESULTADOS}

$\mathrm{Na}$ análise dos questionários sobre a opinião dos pais (Tabela 1), vê-se que a maioria deles considerou a voz de seu filho semelhante à das demais crianças da mesma faixa etária e somente $6(9,1 \%)$ pais caracterizaram a voz de seu filho como sendo pior. Por outro lado $21(31,8 \%)$ deles achou que seu filho fala em maior quantidade se comparado aos colegas. Aproximadamente um quarto (15/22,7\%) dos pais que participaram da pesquisa observou que o volume de voz utilizado pelos seus filhos é aumentado.

Ao opinarem sobre os aspectos comportamentais e de personalidade de seus filhos, os pais foram quase unânimes em afirmar $(49 / 74,2 \%)$ que seus filhos são mais sensíveis que outras crianças de mesma faixa etária (Tabela 1).

Com relação às correlações entre aspectos vocais e de comportamento/personalidade (Tabela 2) pode-se observar que aqueles pais que caracterizaram seus filhos como sendo mais falantes que seus colegas também perceberam a voz deles como sendo mais aguda $(p=0,013)$. $\mathrm{O}$ volume de voz aumentado, bastante evidente nas repostas dos pais, mostrou correlação com agitação $(p=0,044)$, inquietação $(p=0,005)$, sociabilidade $(p=0,021)$, menos quantidade de horas dormidas $(p=0,013)$ e extroversão $(p=0,014)$. As crianças caracterizadas por seus pais como sendo menos falantes o foram também como mais calmas $(p=0,011)$ e menos argumentativas $(p=0,044)$, na comparação com outras crianças (Tabela 2).

Quanto à análise dos aspectos vocais, de comportamento e de personalidade em relação ao sexo, a Tabela 3 apresenta significância apenas quando os pais relataram a presença do aspecto "impulsividade - agir sem pensar" em maior grau nos meninos que nas meninas. Enquanto um total de $28,6 \%$ de meninos foram percebidos pelos pais como sendo impulsivos, apenas $6,5 \%$ de meninas são percebidas dessa maneira $(p=0,02)$.

\section{DISCUSSÃO}

Os pais que participaram da pesquisa forneceram informações valiosas que serão discutidas abaixo e que são indicativas da percepção que têm de seus filhos. A conscientização de pais sobre os aspectos vocais esperados para a infância faz com que eles possam se tornar importantes aliados na identificação precoce dos maus hábitos vocais nas crianças e na busca de soluções para os desvios da voz ${ }^{9}$.

$\mathrm{Na}$ Tabela 1 observam-se os resultados referentes às características vocais relacionadas à qualidade da voz, quantidade de fala, volume e tom de voz. Apesar de os pais terem, em sua maioria, considerado as vozes de seus filhos semelhantes às das demais crianças nos quatro aspectos pesquisados, serão discutidos a seguir os principais desvios observados.

Quanto à qualidade da voz, 9,1\% dos pais consideraram o som da voz de seu filho pior que das demais crianças, porcentagem essa que é semeIhante à descrita em alguns estudos ${ }^{11}$, que sugerem que 6 a $9 \%$ das crianças de escola primária apresenta distúrbio de voz.

Com relação à quantidade de fala, $31,8 \%$ dos pais consideram seu filho mais falante que as demais crianças de mesma faixa etária. Tal resultado pode refletir vários aspectos relacionados ao desenvolvimento da comunicação na infância. A criança que fala muito se revela e compartilha seus sentimentos, vivências e fantasias. Mostra abertura e permite aos pais ter uma noção do que se passa em sua vida. Crianças nos primeiros anos escolares podem também utilizar mais a voz com a intenção de ampliar o seu vocabulário e o círculo de relacionamentos ${ }^{12}$. Falar muito pode vir a se tornar um comportamento vocal abusivo quando o uso intensivo de voz vai além da simples vontade de compartilhar e expor a maneira particular de enxergar o mundo e passa a ser excessivo e incômodo ${ }^{11,13}$. A quantidade aumentada de fala pode ser, nesses casos, indicativa e parte de algum problema maior que a criança apresenta, como ansiedade, agitação e em alguns casos, até TDAH ${ }^{11}$.

O volume de voz aumentado chamou a atenção de $22,7 \%$ dos pais. Sabe-se que crianças de famílias grandes ou com pais muito ocupados, tendem a conquistar seu espaço por meio da voz para não passarem despercebidas ${ }^{14}$. O comportamento vocal dos pais também influencia desde cedo seu aprendizado vocal, uma vez que elas adaptam seu comportamento em resposta ao modelo do adulto. Falar com volume de voz aumentado pode ser também muitas vezes uma forma de chamar a atenção, liderar e tornar-se aceita por um grupo. Somente quando este hábito é prolongado e excessivo é que pode ser caracterizado como comportamento abusivo e inadequado para a voz, que sobrecarrega o aparelho fonador, levando a um desequilíbrio na fisiologia da fonação, podendo produzir alterações na voz que, por vezes, resultam em alterações orgânicas como os nódulos vocais ${ }^{15}$.

Com relação ao tom de voz, as opiniões dos pais se dividiram entre os que consideraram a voz de seus filhos como sendo mais grave $(15,2 \%)$ e aqueles que a consideraram mais aguda $(13,6 \%)$. Algumas pesquisas ${ }^{11}$ indicam que, 6 a $9 \%$ das crianças em idade escolar apresentam alterações 
Tabela 1 - Caracterização dos aspectos vocais, de comportamento e de personalidade, na opinião dos pais, em relação aos colegas de mesma faixa etária

\begin{tabular}{|c|c|c|}
\hline Aspectos vocais & $\mathbf{N}$ & $\%$ \\
\hline \multicolumn{3}{|l|}{ Som da Voz } \\
\hline melhor & 15 & 22,7 \\
\hline pior & 6 & 9,1 \\
\hline semelhante & 45 & 68,1 \\
\hline \multicolumn{3}{|l|}{ Quantidade de fala } \\
\hline mais & 21 & 31,8 \\
\hline menos & 11 & 16,7 \\
\hline semelhante & 34 & 51,5 \\
\hline \multicolumn{3}{|l|}{ Volume de voz } \\
\hline mais alto & 15 & 22,7 \\
\hline mais baixo & 8 & 12,1 \\
\hline semelhante & 43 & 65,1 \\
\hline \multicolumn{3}{|l|}{ Tom da voz } \\
\hline mais agudo & 9 & 13,6 \\
\hline mais grave & 10 & 15,2 \\
\hline semelhante & 47 & 71,2 \\
\hline \multicolumn{3}{|l|}{ Comportamento/personalidade } \\
\hline Crianças mais sensíveis & 49 & 74,2 \\
\hline Crianças mais observadoras & 44 & 66,7 \\
\hline Crianças mais exigentes consigo mesmas & 42 & 63,3 \\
\hline Crianças mais preocupadas & 30 & 45,5 \\
\hline Crianças mais tensas e ansiosas & 26 & 39,4 \\
\hline Criança que se inibe mais com opinião dos outros & 24 & 36,4 \\
\hline Crianças mais tímidas & 22 & 33,3 \\
\hline Crianças com mais hábito de gritar quando aborrecidas & 19 & 28,8 \\
\hline Crianças com mais horas de sono & 19 & 28,8 \\
\hline Crianças mais sociáveis & 17 & 25,8 \\
\hline Crianças mais argumentativas & 17 & 25,8 \\
\hline Crianças com mais acessos de raiva & 16 & 24,2 \\
\hline Crianças com mais sentimento de injustiça & 16 & 24,2 \\
\hline Crianças mais agitadas & 15 & 22,7 \\
\hline Crianças mais medrosas & 14 & 21,2 \\
\hline Crianças mais mal-humoradas/irritadas & 14 & 21,2 \\
\hline Crianças com mais dificuldade de parar & 13 & 19,7 \\
\hline Crianças mais necessitadas de momentos de solidão & 13 & 19,7 \\
\hline Crianças mais bravas quando não satisfeitas & 13 & 19,7 \\
\hline Crianças mais impulsivas/que agem sem pensar & 12 & 18,2 \\
\hline Crianças que mais desrespeitam regras & 10 & 15,2 \\
\hline Crianças mais ciumentas & 9 & 13,6 \\
\hline Crianças que obedecem mais diante de ameaça & 7 & 10,6 \\
\hline Crianças que têm sempre a última palavra & 3 & 4,5 \\
\hline
\end{tabular}


Tabela 2 - Correlações entre aspectos vocais e de comportamento/personalidade

\begin{tabular}{lc}
\hline Aspectos vocais & $\mathbf{P}$ \\
Tom mais agudo e maior quantidade de fala & 0,013 \\
Volume verso comportamento/personalidade & \\
Volume aumentado e maior agitação & 0,044 \\
Volume aumentado e dificuldade de parar quando solicitado & 0,005 \\
Volume aumentado e gostar muito de estar com os amigos & 0,021 \\
Volume aumentado e dormir menos quantidade de horas & 0,013 \\
Volume aumentado e ser mais extrovertido & 0,014 \\
Quantidade de fala verso comportamento/personalidade & \\
Menor quantidade e crianças mais calmas & 0,011 \\
Menor quantidade e crianças menos argumentativas & 0,044 \\
\hline
\end{tabular}

Tabela 3 - Aspectos vocais, de comportamento e de personalidade, em maior grau em relação a outras crianças, de acordo com o sexo, na opinião dos pais

\begin{tabular}{lccccc}
\hline \multirow{2}{*}{ Respostas "Mais” } & \multicolumn{3}{c}{ Fem } & \multicolumn{3}{c}{ Masc } & p-valor \\
\cline { 2 - 5 } & $\mathbf{N}$ & $\%$ & $\mathbf{N}$ & $\%$ \\
\hline Som da voz melhor & 9 & $29,0 \%$ & 6 & $17,1 \%$ & 0,250 \\
Volume da voz mais alto & 6 & $19,4 \%$ & 9 & $25,7 \%$ & 0,538 \\
Tom da voz mais agudo & 5 & $16,1 \%$ & 4 & $11,4 \%$ & 0,579 \\
Maior quantidade de fala & 7 & $22,6 \%$ & 14 & $40,0 \%$ & 0,129 \\
Mais agitado & 4 & $12,9 \%$ & 11 & $31,4 \%$ & 0,073 \\
Mais dificuldade de parar & 5 & $16,1 \%$ & 8 & $22,9 \%$ & 0,493 \\
Prefere estar com amigos & 7 & $22,6 \%$ & 10 & $28,6 \%$ & 0,579 \\
Opinião dos outros inibe mais & 13 & $41,9 \%$ & 11 & $31,4 \%$ & 0,376 \\
Mais tímido & 13 & $41,9 \%$ & 9 & $25,7 \%$ & 0,163 \\
Mais sensível & 23 & $74,2 \%$ & 26 & $74,3 \%$ & 0,993 \\
Mais observador & 22 & $71,0 \%$ & 22 & $62,9 \%$ & 0,485 \\
Precisa mais de momentos de solidão & 8 & $25,8 \%$ & 5 & $14,3 \%$ & 0,240 \\
Mais tenso e ansioso & 13 & $41,9 \%$ & 13 & $37,1 \%$ & 0,691 \\
Mais exigente consigo mesmo & 22 & $71,0 \%$ & 20 & $57,1 \%$ & 0,244 \\
Mais medroso & 7 & $22,6 \%$ & 7 & $20,0 \%$ & 0,798 \\
Mais preocupado & 16 & $51,6 \%$ & 14 & $40,0 \%$ & 0,344 \\
Tem mais acessos de raiva & 8 & $25,8 \%$ & 8 & $22,9 \%$ & 0,780 \\
Tem mais ciúmes & 4 & $12,9 \%$ & 5 & $14,3 \%$ & 0,870 \\
Desrespeita mais as regras & 2 & $6,5 \%$ & 8 & $22,9 \%$ & 0,064 \\
Tenta escapar mais da tarefa argumentando & 5 & $16,1 \%$ & 12 & $34,3 \%$ & 0,092 \\
Tem sempre a última palavra & 0 & $0,0 \%$ & 3 & $8,6 \%$ & 0,095 \\
Obedece mais diante de ameaça de castigo & 1 & $3,2 \%$ & 6 & $17,1 \%$ & 0,067 \\
Se sente mais injustiçado & 8 & $25,8 \%$ & 8 & $22,9 \%$ & 0,780 \\
É mais impulsivo ou age sem pensar & 2 & $6,5 \%$ & 10 & $28,6 \%$ & 0,020 \\
Tem mais mau-humor ou irrita-se & 6 & $19,4 \%$ & 8 & $22,9 \%$ & 0,728 \\
Tem mais o hábito de gritar quando aborrecido & 7 & $22,6 \%$ & 12 & $34,3 \%$ & 0,295 \\
Fica mais bravo quando vontade não én satisfeita & 6 & $19,4 \%$ & 7 & $20,0 \%$ & 0,948 \\
Tem mais horas dormidas & 11 & $35,5 \%$ & 8 & $22,9 \%$ & 0,258 \\
\hline
\end{tabular}


vocais, sendo a alteração mais frequentemente encontrada o nódulo vocal. A voz agravada é uma característica vocal que pode ser precursora da rouquidão e a literatura aponta que tal manifestação pode ser indicativa de nódulos vocais uma vez que estes se encontram presentes em $70 \%$ das crianças roucas $^{11}$. Por outro lado, a voz aguda pode, em alguns casos, ser reflexo de tensão dos músculos intrínsecos da laringe resultante de estados de ansiedade ${ }^{16}$.

Com relação aos itens comportamentais e de personalidade (Tabela 1), serão discutidos a seguir os três aspectos mais observados pelos pais (acima de 50\%), a saber: "você acha seu filho mais sensível que as outras crianças" (74,2\%), "você acha que seu filho é mais observador que as outras crianças" $(66,7 \%)$ e "você acha que seu filho é mais exigente consigo mesmo que as outras crianças" (63,3\%). 0 número elevado de pais - com a opinião de que seu filho é mais sensível, observador e exigente consigo mesmo - pode, por um lado, ser indicativo de que subjetivamente estes consideram seus filhos como sendo únicos, especiais e frágeis e por outro lado, refletir objetivamente o dado de realidade de que crianças em crescimento podem mesmo ser sensíveis em relação às influências do meio que as circunda; podem ser também observadoras, talvez como forma de aprendizado e internalização dos hábitos e culturas que as cercam assim como podem também ser exigentes consigo mesmas na medida em que procuram corresponder às expectativas dos pais, professores e colegas, em busca de competência social e empatia ${ }^{17}$.

Quando se investigou a correlação entre volume de voz aumentado e os aspectos comportamentais e de personalidade (Tabela 2), observou-se que as crianças que falam alto - assim descritas por seus pais - são as mesmas que os pais enxergam como sendo agitadas $(0,044)$, inquietas $(0,005)$, sociáveis - gostam de estar com os amigos - $(0,021)$, que dormem menos horas que seus colegas $(0,013)$ e que são extrovertidas $(0,014)$. A agitação e inquietação motora quando associadas à impulsividade e à falta de atenção, podem favorecer comportamentos vocais abusivos como: falar muito ou com velocidade de fala aumentada, gritar e ataque vocal brusco ${ }^{11}$. Um autor ${ }^{18}$ comenta que as crianças agitadas podem ter a fala especialmente alta e desinibida. O mesmo autor considera que duas forças agem na psique ou constituição emocional do ser humano: de um lado estaria a simpatia ou amor que o instiga a ser extrovertido, intencional, ativo e é a base de todos os sentimentos humanos, incluindo igualmente amor e ódio. De outro lado estaria a força da antipatia através da qual se rejeita, mantém-se as coisas afastadas, não se é extrovertido nem intencional, não se é determinado por vontades nem desejos, mas antes se é separado, por ela, das experiências vividas. Este seria o agente que possibilita formar impressões, reconhecer coisas e, no fim, formar opiniões. Na criança agitada e inquieta, o equilíbrio entre ambas estaria perturbado e a força da simpatia pareceria "afogar" a força da antipatia. Recomenda que tais crianças sejam poupadas e que não se deve expô-las a demasiados estímulos rapidamente mutáveis.

Alguns autores ${ }^{19}$ afirmam que a personalidade envolve componentes orgânicos e herdados assim como componentes sócio-culturais que são produtos de aprendizagem. Contudo, certas tendências são percebidas nos processos de modificação e reorganização da personalidade que diferenciam um sujeito do outro. Nesse sentido, cada um tem que lidar com seus motivos pessoais e as influências ambientais, que nem sempre são favoráveis, promovendo reajustes em seu comportamento. Sua teoria considera a personalidade como uma hierarquia de traços que seriam tendências duradouras, modos de comportar-se em uma diversidade de situações. Em decorrência, a tendência de uma pessoa a ser impulsiva, agitada, irascível, impetuosa e impaciente poderia ser decorrente da tendência mais básica de ser excitável. Vê-se assim, que os autores, apesar de terem explicações e visões diversas sobre os comportamentos observados, parecem unânimes em afirmar que tais crianças com as características descritas são aquelas que, por um motivo ou outro, parecem precisar de um cuidado especial na estruturação e organização da rotina diária. Os pais, que perceberam tão bem a sensibilidade de seus filhos, precisam incluí-la e respeitá-la, assim como se conscientizar de que quando seu filho fala muito ou muito alto no dia a dia, isto pode ser indicativo de excesso de estimulação e consequente excitação ${ }^{20}$.

Com relação às horas de sono dormidas (Tabela 2), os pais das crianças que falam com volume de voz aumentado percebem também que elas dormem menos $(p=0,013)$, em relação aos colegas de mesma faixa etária. Serrão, Klein, Gonçalves ${ }^{21}$ observaram em seus estudos, que $8 \%$ de crianças em idade escolar apresenta sintomatologia de sono. Os autores observaram uma melhora da qualidade do sono ao longo do ano letivo, provavelmente porque o contexto escolar parece ser extremamente estruturado por suas rotinas e regras e, principalmente, por seus horários, o que, por conseguinte, tem impacto ao nível da higiene de sono (estruturação do padrão de sono) das crianças. Uma pobre qualidade de sono associa-se a queixas de humor, como fadiga, ansiedade, irritabilidade e humor depressivo, bem como a déficits no nível do funcionamento cognitivo, como o 
decréscimo de atenção, motivação e eficiência. Dormir bem e descansar são hábitos considerados saudáveis para a voz ${ }^{2}$. Mais um aspecto a ser considerado pelos pais na estruturação da rotina de seus filhos sensíveis.

Falar em maior quantidade e também com voz mais aguda $(p=0,013)$ como se observa na Tabela 2 pode ser reflexo de estados de ansiedade ${ }^{16}$. Ao passo que falar em menor quantidade parece ser o reflexo de calma $(0,011)$ e pouca necessidade de argumentação $(0,044)$, uma vez que os pais que consideraram seus filhos mais calmos e menos argumentativos são também os que consideraram que eles falam menos que as demais crianças de mesma faixa etária.

$\mathrm{Na}$ comparação entre os sexos (Tabela 3), observa-se que meninos são considerados mais impulsivos - agem sem pensar, que as meninas $(p=0,020)$. Do ponto de vista sócio-cultural, é esperado que meninos sejam mais ativos e consequentemente mais impulsivos ${ }^{22}$. Segundo alguns estudos $^{23}$, há mais meninos com alto grau de impulsividade e a impulsividade reflete um sistema neurobiológico distinto do das meninas. Alguns autores ${ }^{6,7,10}$ relacionam em seus estudos extroversão e impulsividade com presença de nódulos vocais em crianças. No presente estudo, a impulsividade não apresentou correlação positiva com os aspectos vocais estudados.

Acredita-se que seja importante a conscientização dos pais de crianças que procuram atendimento fonoaudiológico por disfonia e dos professores que têm em sala de aula tanto as crianças disfônicas como aquelas com risco de desenvolver disfonia, de aspectos que envolvam voz, comportamento e personalidade, pois podem ser sinalizadores e indicadores de atuais ou futuros desvios vocais e também da importância do envolvimento dos pais no processo preventivo/terapêutico ${ }^{19}$. Merecem a atenção não só aspectos de higiene vocal ${ }^{24}$, bem como o cuidado com a rotina diária - que não contenha excesso de estimulação e não promova a excitação - e também a estruturação dos hábitos de sono dessas crianças. Para o sucesso do tratamento fonoaudiológico é importante a conscientização da necessidade de se abordar os aspectos citados na terapia fonoaudiológica da criança disfônica, uma vez que a voz, sendo transmissora de mensagens verbais e emocionais, extrapola 0 treino de mecanismos puramente fisiológicos.

\section{CONCLUSÃO}

Por meio da análise das respostas dos pais ao questionário sobre características vocais, de comportamento e de personalidade de seus filhos, conclui-se que:

Embora a maioria dos pais tenha opinião positiva sobre a voz de seus filhos, a quantidade de fala elevada foi a característica mais bem percebida por eles. Os pais também percebem desvios de frequência na voz de seus filhos;

Volume de voz aumentado se correlacionou com maior agitação, inquietação, sociabilidade, extroversão e menor quantidade de horas dormidas;

Enquanto quantidade de fala aumentada se correlacionou com voz mais aguda; menor quantidade de fala se correlacionou com maior calma e menor necessidades de argumentação;

Meninos são percebidos como mais impulsivos - agem sem pensar. 


\section{ABSTRACT}

Purpose: to check how parents perceive and describe their children with 'regard to their voice and behavior and personality traits. Methods: the study involved the participation of 66 parents of children between 6 and 9 year old, from both genders, who answered a questionnaire with 28 questions addressing voice, behavior and personality traits of their children. Results: results indicated that the majority of the parents $(90.9 \%)$ perceived themselves satisfied with the sound of their child's voice. Only $9.1 \%$ of the parents characterized the voice of their child as being worse than other children and $31.8 \%$ felt that their child speaks more compared to his/her friends. Approximately a quarter $(22.7 \%)$ of the parents observed that the voice volume used by their children is higher. The parents that characterized their children as being more talkative also perceived their voices as having a higher pitch $(p=0.013)$. The increased voice volume showed a positive correlation with agitation $(0.044)$, restlessness (0.005), sociability (0.021), less hours of sleep (0.013) and extroversion (0.014). Children characterized as being calmer $(p=0.011)$ and less argumentative $(p=0.044)$ were also seen as less talkative compared to other children. Conclusion: in general, the parents seem to notice vocal traits in their children, they have a strong trend to consider their children as sensitive, observant and demanding in relation to themselves, in addition to noting a relationship among voice volume and behavior and personality traits.

KEYWORDS: Dysphonia; Voice; Parents; Children

\section{REFERÊNCIAS}

1. Behlau M, Azevedo R, Pontes P. Conceito de voz normal e classificação das disfonias. In: Behlau M. Voz: o livro do especialista. Vol 1. Rio de Janeiro: Revinter; 2001. p.53.

2. Teixeira MZM, Trezza EMC, Behlau M. Opinião dos pais sobre a voz de seus filhos de 5 a 12 anos. Rev Paul Pediatr. 2003; 21(2):68-75.

3. Harty M, Alant E, Uys CJE. Maternal selfefficacy and maternal perception of child language competence in pre-school children with a communication disability. Child:care, health and development. 2006; 33(2):144-54.

4. Hurtado MMT, Gonzalez FS, Iglesias VF, Barandián UA. Voz del niño. Rev. Med. Univ. Navarra. 2006; 50(3):31-43.

5. Roy N, Holt KI, Redmond S, Muntz H. Behavioral characteristics of children with vocal fold nodules. J Voice. 2007; 21:157-68.

6. Behlau M, Madazio G, Pontes P. Disfonias organofuncionais. In: Behlau M. Voz: o livro do especialista. Vol 1. Rio de Janeiro: Revinter; 2001. p.296.

7. Takeshita TK, Ricz LA, Isaac ML, Ricz H, Lima WA. Comportamento vocal de crianças em idade Pré-escolar. Arq. Int. Otorrinolaringol. 2009; 13(3):252-8.

8. Seifert E, Kollbrunner J. Stress and distress in non-organic voice disorder. Swiss Med. Wkly. 2005; 135: 387-97.
9. Connor NP, Cohen SB, Theis SM, Thibeault SL, Heatley DG, Bless DM. Attitudes of children with dysphonia. J Voice. 2008; 22:197-209.

10. Markham C, Dean T. Parents' and professionals' perception of quality of life in children with speech and language difficulty. Int. J. Lang. Comm. Dis. 2006; 41(2):189-212.

11. Maia AA, Gama ACC, Michalick-Triginelli MF Relação entre transtorno do déficit de atenção/ hiperatividade, dinâmica familiar, disfonia e nódulo vocal em crianças. Rev. Ciênc Méd. 2006; 15(5):379-89.

12. Tittmann M. Das Wort als Weg In: Lautwesenskunde Erziehung und Sprache. Stuttgart: Verlag Freies Geistesleben GmbH; 1979. $40 \mathrm{p}$

13. Coughlin-woods S, Lehman ME, Cooke PA. Ratings of speech naturalness of children ages 8-16 years. Perceptual and Motor Skills. 2005; 100: 295-304.

14. Behlau MS, Gonçalves MIR. Considerações sobre disfonia infantil. In: Ferreira LP, organizador. Trabalhando a voz: vários enfoques em fonoaudiologia. São Paulo: Summus; 1988. p.99.

15. Teig CBS. Nódulos vocais em crianças pequenas [monografia]. São Paulo (SP): CEFAC Pós-Graduação em Saúde e Educação;1997

16. Behlau M, Rehder MI, Azevedo R, Bortolotti EL. Disfonias psiquiátricas In: Behlau $\mathrm{M}$, organizador. Voz: o livro do especialista. Vol. 2. Rio de Janeiro: Revinter; 2005. p.79. 
17. Oliveira EZ. Psicologia das habilidades sociais na infância. Teoria e prática. Aval. Psicol. 2005;4(1): 91-3.

18. Weihs TJ. A criança agitada In: Weihs TJ. Crianças que necessitam de cuidados especiais. São Paulo: Ed. Antroposófica; 1984. p.61.

19. Sisto FF, Oliveira SMSS, Oliveira KL, Bartholomeu D, Oliveira JC, Costa OR. Escala de traços de personalidade para crianças e aceitação social entre pares. Intera Psicol. 2004; 8(1):5-24.

20. Baker J. The role of psychogenic and psychosocial factors in the development of functional voice disorders. Int. Journal of Speech-Language Pathology. 2008; 10(4):210-30.

21. Serrão F, Klein JM, Gonçalves A. Qualidade do sono e depressão: que relações sintomáticas em crianças de idade escolar. PsicoUSF. 2008; 13(1):257-68.

22. Lisboa CSM. Estratégias de coping e agressividade: um estudo comparativo entre crianças vítimas e não vítimas de violência doméstica [dissertação]. Porto Alegre (RS): Universidade Federal do Rio Grande do Sul; 2001. 23. Côté S, Trembley RE, Nagin D, Zoccolillo $M$, Vitaro F. The development of impulsivity, fearfulness and helpfulness during childhood: patterns of consistency and change in the trajectories of boys and girls. J Child Psychol Psychiatr. 2002; 43(5):609-18.

24. Hooper CR. Treatment of voice disorders in children. Langauge, Speech and Hearing Services in School. 2004; 35:320-6.

DOI: 10.1590/S1516-18462010005000083

RECEBIDO EM: 03/12/2009

ACEITO EM: 13/04/2010

Endereço para correspondência:

Angela von Fritsch

Al. Das Quaresmeiras, 80

São Paulo - SP

CEP: 04716-070

E-mail: fono@angelavf.fnd.br 